Revistade
Economild
Contemporâned

\title{
TEORIA ECONÔMICA E POLÍTICA DE INOVAÇÃO
}

\author{
Achyles Barcelos da Costa ${ }^{a}$ \\ aProfessor titular aposentado da Universidade Federal do Rio Grande do Sul (UFRGS) \\ e colaborador do Programa de Pós-graduação em Economia da UFRGS.
}

Artigo recebido em 24/08/2015 aprovado em 04/08/2016.

RESUMO: O objetivo do trabalho, como o seu título indica, consiste em identificar a teoria econômica que informa a política tecnológica. A metodologia utilizada está fundamentada em revisão de literatura, na qual se procurou verificar o lugar que a inovação ocupa em diferentes escolas do pensamento econômico. A literatura resenhada mostra que a teoria neoclássica e a teoria evolucionária são aquelas abordagens que têm se ocupado de maneira mais direta com a política industrial, nela incluída a política de inovação. As avaliações críticas sobre a teoria neoclássica são de que a sua ótica baseada nas "falhas de mercado" apresenta deficiências no tratamento da inovação, o que a torna limitada enquanto base conceitual para a política pública. A teoria evolucionária, com o seu conceito de sistema de inovação, dá um tratamento analítico mais elaborado ao processo de geração e difusão tecnológica, preconizando uma política pública baseada na ótica sistêmica da inovação.

PALAVRAS-CHAVE: inovação; teoria econômica; política de inovação; falhas de mercado; sistema de inovação.

CLASSIFICAÇÃO JEL: O31; O38. 


\title{
ECONOMIC THEORY AND INNOVATION POLICY
}

\begin{abstract}
This paper aims to, as its title proposes, identify the segment of economic theory that speaks of technological policy. The methodology used is based on literature review, which sought to verify the place that innovation holds in different schools of economic thought. The literature review shows that the neoclassical theory and the evolutionary theory are the approaches that have been mostly concerned with industrial policy issues, including the innovation policy related ones. Critics of the neoclassical theory argue that its "market failure"-based perspective presents shortcomings when it comes to the treatment of innovation, which makes it limited as a conceptual basis for public policy. Evolutionary theory with its concept of innovation system gives a more elaborate analytical treatment to the process of technology creation and diffusion, since it advocates for public policy based on a systemic innovation perspective.
\end{abstract}

KEYWORDS: innovation; economic theory; innovation policy; market failures; innovation system. 


\section{INTRODUÇÃO}

O objetivo deste estudo é identificar os fundamentos econômicos que informam a política tecnológica ou de inovação ${ }^{1}$. Isto é feito mediante revisão de literatura em que se procura selecionar aqueles corpos teóricos que mais explicitamente abordam o tema da inovação e suas recomendações de política pública. A ideia é realizar uma avaliação de como a inovação é tratada pelos diferentes ramos da teoria econômica, bem como o papel que o mercado e o Estado desempenham na sua promoção.

O trabalho está organizado em mais três seções, além desta introdução. Na segunda, percorre-se a literatura, em seus distintos matizes, com o objetivo de observar o caráter que a inovação ocupa na compreensão da dinâmica econômica e as categorias analíticas empregadas para tal. A partir dessa revisão, percebe-se que a teoria neoclássica e a teoria evolucionária são aquelas abordagens que mais têm derivado recomendações de ações públicas para lidar com a inovação. Na terceira seção, desenvolvem-se, de maneira mais detalhada, as bases de orientações de políticas que podem ser originadas dessas concepções teóricas sobre o papel da inovação na economia. Na quarta seção, é feito um apanhado geral do trabalho realizado, no qual são apontadas as principais deficiências da abordagem neoclássica no tratamento da inovação e da política pública, e os argumentos de como a teoria evolucionária se mostra mais bem preparada na consideração dessas questões.

\section{O CARÁTER DA INOVAÇÃO NA TEORIA ECONÔMICA}

A influência da inovação na vida em sociedade desde cedo esteve presente na análise econômica, enquanto ramo particular do conhecimento. Os economistas da escola clássica, particularmente Adam Smith e David Ricardo, dedicaram atenção a esse fenômeno. O mesmo pode ser dito em relação a Karl Marx, um crítico daquela escola.

Na Riqueza das Nações, em seu capítulo inicial sobre a divisão do trabalho, Smith ([1776]1958) menciona o aumento de produtividade que pode ser alcançado na fabricação de alfinetes mediante a divisão técnica do trabalho nessa atividade, através da especialização de tarefas exercidas pelos trabalhadores. Igualmente, aduz que o conhecimento necessário ao melhor desempenho fabril poderia provir não só dos fabricantes de máquinas, mas, também, daquelas pessoas dedicadas à filosofia, ou seja, ocupadas com o conhecimento científico. 1 Política tecnológica e política de inovação serão expressões utilizadas de maneira intercambiável neste
texto. 
O progresso técnico aparece na obra de David Ricardo quando da terceira edição em 1821 de seus Princípios de Economia Política e Tributação, estudo originalmente publicado em 1817, quando adiciona o célebre capítulo “Sobre a Maquinaria”. Nele, Ricardo analisa a influência que a substituição de mão de obra pela maquinaria exerce sobre o emprego e os salários dos trabalhadores (RICARDO, [1817/1821]1982). Mas, tanto para Smith quanto para Ricardo, o tratamento do progresso técnico não vai além de seus efeitos sobre a atividade econômica.

No âmbito da teoria desenvolvida por Marx, é reconhecido o papel do progresso técnico na explicação da dinâmica econômica capitalista. Apenas para fazer um paralelo, há muita semelhança entre a ideia de destruição criadora de Schumpeter ([1942]1984), em que a inovação é vista como o motor do desenvolvimento econômico e expressões encontradas, por exemplo, no Manifesto Comunista de Marx e Engels ([1848]2010, p. 43) como:

A burguesia não pode existir sem revolucionar incessantemente os instrumentos de produção [...] Essa subversão contínua da produção, esse abalo constante de todo o sistema social, essa agitação permanente e essa falta de segurança distinguem a época burguesa de todas as precedentes.

Para Marx, o desenvolvimento das forças produtivas leva, em determinados momentos da história, a que se rompam as relações de produção que foram por aquelas engendradas. Em sua obra intitulada Miséria da Filosofia, dedicada a uma crítica a Proudhon, Marx coloca essa avaliação claramente:

Ao adquirir novas forças produtivas, os homens mudam o modo de produção, e ao mudar o modo de produção e a maneira de ganhar a vida, alteram-se todas as relações sociais. O moinho movido manualmente nos dá a sociedade dos senhores feudais; o moinho a vapor, a sociedade dos capitalistas industriais. (MARX, [1847]1974, p. 91)

As passagens acima deram margem, equivocadamente, como bem assinalada por Schumpeter ([1942]1984, p. 28-29) e também por Rosenberg ([1982]2006, p. 70), a interpretações de um determinismo tecnológico por parte daquele pensador alemão. Para Marx, no entanto, as relações sociais não são meros elementos passivos a atuar na sociedade. Elas levam também a que se desenvolvam novos instrumentos de produção. Há uma interação dialética entre forças produtivas e relações sociais de produção, embora, ao fim e ao cabo, as primeiras predominem, pois é nesse âmbito que os homens retiram sua vida material e que vão determinar sua consciência social. 
Outros usos que Marx faz da tecnologia podem induzir, também, a que se interprete o tipo de inovação por ele considerado como tendo um caráter restrito, basicamente de processo de produção ou operacional, quando, por exemplo, em O Capital (MARX, [1867]1983/1984) critica a "teoria da compensação" acerca do desemprego tecnológico ou quando discute os conceitos de mais valia absoluta e de mais valia relativa, particularmente na influência que esta última exerce sobre a recuperação da taxa de lucro. Nesse último caso, de maneira simplificada, pode-se argumentar que, segundo Marx, quando ocorre a expansão da acumulação de capital, há uma tendência de elevação dos salários decorrente da maior demanda por mão de obra, comprimindo os lucros. Para recuperar a margem de lucro, o capitalista intensifica a mecanização do processo produtivo, substituindo trabalho vivo mediante investimentos em capital constante - máquinas e equipamentos -, elevando, assim, a composição orgânica do capital, bem como recompondo o exército industrial de reserva, de modo a manter os salários ao nível de subsistência do trabalhador. Sem dúvida, este é um dos usos mais explícitos da tecnologia que Marx faz na análise do capitalismo. Porém, como assinalado por Rosenberg ([1982]2006), não é adequado interpretar que Marx considerasse a tecnologia apenas como poupadora de mão de obra. Não se pode deixar de reconhecer que ele também concebia a tecnologia de maneira holística, tendo um papel mais amplo na sociedade. Cabe aqui fazer referência novamente ao já citado Manifesto Comunista:

A burguesia, em seu domínio de classe de apenas um século, criou forças produtivas mais numerosas e mais colossais do que todas as gerações passadas em conjunto. A subjugação das forças da natureza, as máquinas, a aplicação da química na indústria e na agricultura, a navegação a vapor, as estradas de ferro, o telégrafo elétrico, a exploração de continentes inteiros, a canalização dos rios, populações inteiras brotando da terra como por encanto - que século anterior teria suspeitado que semelhantes forças produtivas estivessem adormecidas no seio do trabalho social? (MARX e ENGELS, [1848]2010, p. 44)

E, na sequência dessa passagem, pode-se deduzir o caráter de path dependency das inovações, enquanto oriundas em um contexto institucional prévio, decorrente de suas limitações produtivas, quando afirmam que "[...] os meios de produção e de troca, sobre cuja base se ergue a burguesia, foram gerados no seio da sociedade feudal" (MARX e ENGELS, [1848]2010, p. 44).

Convém ressaltar, contudo, que, apesar da importância que Marx atribuía ao papel da tecnologia no desenvolvimento dos modos de produzir em sociedade, ele não estava preocupado com a mudança tecnológica per se. O seu objetivo último era enten- 
der o processo de mudança histórica desses modos de produção, em particular em relação ao capitalismo. Entretanto, diferentemente de Schumpeter, para Marx, o drive dessa mudança histórica encontra-se na luta de classes.

Enfim, Marx não se propôs a teorizar a mudança tecnológica, embora, como Rosenberg ([1982]2006, p. 68) faz notar, ele seja um importante ponto de partida nessa direção.

No que se refere à teoria keynesiana, a preocupação de pesquisa está centrada em variáveis macroeconômicas representadas, entre outras, pelo produto, o emprego e o dinheiro (KEYNES, [1936]1983). Segundo Freeman e Perez (1988), embora Keynes, no Treatise on Money, tivesse mencionado certa concordância com Schumpeter na influência da inovação na decisão de investimento, ele e os seus discípulos não seguiram nessa linha.

A política pública keynesiana está orientada para os aspectos fiscais e monetários de estabilização da economia, fixada para criar o ambiente amigável que mitigue a incerteza e facilite as tomadas de decisões de investimento. O progresso técnico, caso esteja presente na investigação teórica, tem um papel marginal, não sendo conferida a ele uma função conceitualmente importante. O interesse analítico é com os determinantes do emprego, não da tecnologia (PETIT, 1995). No caso de insuficiência de demanda efetiva, essa teoria considera que a atribuição do Estado é agir por meio de políticas e ações que levem à retomada dos investimentos na economia. As incursões produtivas do Estado são de caráter complementar ao interesse privado e em atividades que criem poder de compra, incentivem o consumo e elevem a demanda agregada. No que tange aos investimentos privados, eles dependem do animal spirit, do cálculo empresarial sobre a eficiência marginal do capital investido. Mas a natureza e direção setorial dos investimentos, tanto públicos quanto privados, é uma incógnita, até porque a insuficiência de demanda efetiva, para essa teoria, não tem como causa algum elemento de natureza tecnológica, sendo atribuída a fatores relacionados à forma de manter a riqueza - representada pelo dinheiro - e à sua aplicação na economia. Ainda de acordo com as palavras de Freeman e Perez (1988, p. 44, grifos no original, tradução nossa):

Nós podemos argumentar que as análises e as políticas keynesianas foram e são deficientes no que se refere às alterações de longo prazo na tecnologia em seus efeitos sobre a confiança nos negócios, na mudança estrutural na economia e nas especificidades do investimento em infraestrutura. Quase todas as análises e modelagens macroeconômicas neokeynesianas (entre outras) são restritas a aspectos puramente quantitativos do investimento e do emprego, enquanto Schumpeter corretamente insistia na importância crucial dos aspectos qualitativos. 
No sentido discutido por Freeman e Perez (1988), portanto, a política pública de cunho keynesiano não possui um foco específico sobre o fomento à inovação, priorizando a geração de emprego e renda no sentido geral. Obviamente, os gastos governamentais também podem ser direcionados para estimular a inovação, mas essa não é uma medida explícita indicada pela política keynesiana.

O surgimento da escola neoclássica, a partir dos anos 1870, não avançou o conhecimento teórico acerca da inovação além daquele mencionado em Smith, Ricardo e Marx. Ao contrário, a emergência desta escola levou ao abandono da inovação como objeto de preocupação na explicação da dinâmica econômica (NELSON, 1998). A agenda de pesquisa dos economistas dessa corrente voltou-se para as condições a serem estabelecidas para uma alocação ótima de recursos, com pouca ou nenhuma abertura para a inclusão da inovação como um objeto particular de investigação. Não se procurava saber as suas origens econômicas e tampouco a inovação recebia um tratamento teórico especial como uma variável determinante na explicação do desempenho econômico, seja de empresas ou de países².

Apenas nos anos 1950, é que essa escola passa a dar alguma atenção à inovação. De um modo geral, pode-se, seguindo Nelson (1998), dividir os estudos nessa área em dois tipos: os "antigos" e os "novos" modelos de crescimento. A distinção refere-se a que os primeiros tratam o progresso técnico como sendo exógeno à atividade econômica, enquanto os segundos tentam de alguma forma endogeneizá-lo.

O início da discussão pode ser estabelecido com os trabalhos de Moses Abramovitz e de Robert Solow. Em seus estudos pioneiros sobre a quantificação dos determinantes do crescimento do produto per capita dos Estados Unidos feitos por Solow ([1957]1979), compreendendo o período 1909-1949, e por Abramovitz ([1956]1979), para o intervalo 1869-1953, encontrou-se que o desempenho econômico daquele país devia-se muito pouco ao emprego dos fatores de produção de capital e de trabalho. De acordo com Solow, a parte não explicada do crescimento pelo uso daqueles fatores de produção alcançava $87,5 \%$ do total do crescimento. O tamanho desse resíduo, conforme salientou Abramovitz, daria - para usar a frase desse autor que se popularizou na literatura - "uma medida de nossa ignorância” sobre as causas do crescimento econômico. De acordo, ainda, com as palavras de Abramovitz:

2 Convém, contudo, mencionar que Marshall ([1890/1920]1982, Livro IV, capítulo VI: A aprendizagem industrial) procurou estabelecer o papel que a educação geral, técnica e artística desempenhava no aumento da eficiência industrial. Alerta, inclusive, embora de maneira breve, para a relevância que teriam nas invenções industriais. Marshall mostra como a importância e a concepção dessas aptidões da população se modificam com o tempo e variam também no espaço. Entretanto, esse veio histórico-empírico de Marshall, desde então, acabou relegado ao esquecimento pelos seus epígonos, preocupados apenas como a alocação ótima dos recursos entre usos alternativos. 
A principal fonte do grande incremento no produto líquido per capita [nos Estados Unidos] não se deveu a um aumento do insumo de mão de obra per capita, nem sequer de um aumento do capital per capita, tal como convencionalmente esses recursos são concebidos e medidos. Sua fonte deve ser buscada, sobretudo, no complexo de forças pouco claras que fizeram aumentar a produtividade, ou seja, o produto por unidade de recursos utilizados. (ABRAMOVITZ, [1956]1979, p. 298, tradução nossa)

No enfoque neoclássico padrão que se difundiu, baseados em estática comparativa e em modelos de equilíbrio geral, o progresso técnico, quando muito, aparece incorporado ao conceito de função de produção, mas, nesse caso, não se sabe como é criado, como se difunde no tecido econômico e nem como muda ao longo do tempo. Na empresa neoclássica, segundo essa abordagem, a tecnologia atua apenas na relação entre produto e fatores produtivos, estabelecida pela função de produção, poupando algum dos fatores ${ }^{3}$ ou sendo neutra em relação às suas combinações. Inexiste a preocupação com os aspectos qualitativos do crescimento econômico. Esta afirmação vale tanto para os novos produtos, modificando as preferências de consumo no mercado, quanto para novos processos de fabricação e formas organização da produção, causando o deslocamento da função de produção das empresas. $\mathrm{O}$ objeto do tratamento teórico neoclássico é a alocação de recursos e não como esses recursos são criados. Os agentes econômicos apresentam-se atomizados e com comportamento otimizador, sendo guiados em suas ações pelas livres forças de oferta e demanda de mercado. Nesse mundo idílico, o crescimento econômico e o bem-estar da população são alcançados automaticamente, desde que, obviamente, os agentes obedeçam aos sinais emitidos pelo mercado através do sistema de preços, o que resultaria em uma alocação considerada "eficiente". Esse desiderato, contudo, somente não será atingido caso sobrevenham comportamentos desviantes, oportunistas ou ingerências indevidas por parte do Estado e que extrapolem as suas funções de garantir a ordem e a segurança da sociedade, bem como os contratos livremente pactuados ${ }^{4}$.

Contudo, mesmo no seio neoclássico, por volta dos anos 1980, observava-se certo desconforto com as críticas feitas àquela análise bastante restritiva em relação ao progresso técnico, que ignorava os retornos provenientes do conhecimento e, em decorrência, a possível existência de mercados imperfeitamente competitivos. A resposta neoclássica a essas críticas, denominada na literatura de "modelo de crescimento endógeno",

3 Vide, por exemplo, o capítulo I: “A mola mestra do crescimento econômico", de Hicks ([1977]1978).

4 Na próxima seção, em que se discutirá o papel do Estado na ótica neoclássica, será examinada a inovação no âmbito das "falhas de mercado". 
buscou tratar o progresso técnico como oriundo do próprio funcionamento do mercado ao considerar que os chamados agentes produtivos teriam incentivos econômicos ao realizar investimentos intencionais na produção privada de conhecimento. A abordagem básica para a modelagem seria supor o crescimento econômico como sendo guiado pela acumulação de conhecimento por agentes maximizadores, o que produziria, então, um modelo de crescimento de equilíbrio competitivo (ROMER, 1986).

O conhecimento é interpretado como sendo um bem (de capital) distinto dos bens convencionais e dos bens públicos em sentido estrito. Ele seria um tipo particular de bem público, com a propriedade de, além de não rival, ser parcialmente exclusivo, ou seja, seria passível de produzir retornos a serem apropriados privadamente (ROMER, 1990). Porém, mesmo essa tentativa carece, segundo Nelson $(1997,1998)$, de maior realismo, posto que se prende aos supostos de agentes otimizadores, de equilíbrio do sistema, com uma limitada teoria da firma e do arranjo institucional ${ }^{5}$. Explicitamente, o modelo de crescimento endógeno considera que a incerteza é redutível a risco, de modo que os agentes conseguiriam fazer um cálculo de otimização da alocação eficiente de recursos em P\&D. Além disso, considera-se que o único mecanismo de apropriação sejam os direitos de propriedade - nesse caso, patentes industriais -, sendo o modelo mudo a respeito de outras formas de defesa dos ganhos da inovação, como, por exemplo, os segredos industriais e a prática de lead time. Contudo, a maior parte da ortodoxia ainda continua com suas análises de política pública baseadas na ideia de "falhas de mercado".

A preocupação mais sistemática e focada na inovação como uma variável central na explicação do desenvolvimento econômico vai ter a edificação de suas bases teóricas a partir de Schumpeter. O marco desse esforço é a sua obra escrita em 1911, intitulada The Theory of Economic Development ${ }^{6}$. Nela, Schumpeter ([1911/1934]1982, p. 48-49) estabelece os fundamentos da mudança econômica, que ele chamou de novas combinações: a introdução de um novo bem; a aplicação de um novo método de produção; a abertura de um novo mercado; a descoberta de uma nova fonte de matéria-prima; o estabelecimento de uma nova forma de organização da indústria. Nesse e em outros escritos, como em Business Cycle (SCHUMPETER, 1939) e Capitalism, Socialism, and Democracy, de 1942, Schumpeter vai apontar para a característica disruptiva do desenvolvimento capitalista, alternando períodos de expansão da produção secundados por fases de depressão. O que dá forma a tal tipo de movimento não são aqueles aperfeiçoamentos produtivos que ocorrem continuamente no dia a dia da atividade econômica,

\footnotetext{
5 Uma apreciação dos modelos de crescimento endógeno pode ser encontrada também em Verspagen (2006). Na avaliação de Lazonick (1994, p. 7): "Mainstream economics contains no theory of innovation and no theory of competitive advantage".

${ }_{6}$ A edição modificada e publicada em definitivo em inglês, difundindo-se na literatura, data de 1934.
} 
as chamadas inovações incrementais, mas as novidades de caráter radical que alteram a trajetória do movimento, gerando rupturas e descontinuidades no processo de crescimento econômico. É uma mudança muito mais de natureza qualitativa do que quantitativa, que altera por dentro a própria estrutura do sistema. Essas tecnologias superiores em relação àquelas em uso são as que causam o desenvolvimento econômico. A metodologia de análise da economia tem de estar baseada no desequilíbrio e na história, por ser este um processo evolutivo em que o hoje carrega os genes de seu passado.

Em um sistema econômico onde prevalece a propriedade privada dos meios de produção, a divisão do trabalho aí existente gera interdependência entre os agentes econômicos (empresas, consumidores, trabalhadores), bem como produz decisões econômicas individuais descentralizadas. A coordenação do sistema, de modo a produzir ordem em seu funcionamento, é feita pelo mercado através do mecanismo de preços, regulado pela livre concorrência entre esses agentes em suas interações. A empresa é o principal lócus onde ocorre a produção de riqueza nesse sistema. A busca de lucros orienta as suas estratégias competitivas no mercado. A obtenção de lucros extraordinários, de acordo com Schumpeter, está na introdução de inovações, naquele sentido amplo dessa categoria de análise ${ }^{7}$. O caráter transitório desses lucros deve-se à finitude das oportunidades de desenvolvimento de uma dada inovação, que têm tanto causas técnicas quanto econômicas: técnicas, no sentido de que ocorrem limites nas potencialidades tecnológicas a serem exploradas; econômicas, porquanto a leva de imitadores que surge para se beneficiar das oportunidades de ganhos proporcionadas pela inovação tende a eliminar os lucros extraordinários, através da queda dos preços, devido à maior oferta do novo produto.

Uma questão lógica que se colocou a Schumpeter refere-se à origem das inovações. Quem as introduz no sistema? Inicialmente, na Teoria do Desenvolvimento Econômico, Schumpeter atribui o fenômeno a uma categoria especial de pessoas dotadas de energia, inteligência, visões e iniciativas não difundidas entre toda a população. Trata-se do entrepreuneur, do empresário inovador, que é responsável por lançar "novas combinações" na economia. Mas não há em Schumpeter uma teoria que dê status analítico-conceitual a esse tipo de indivíduo. Ele não precisa fazer parte necessariamente da classe de capita-

\footnotetext{
Schumpeter ([1942]1984, capítulo III) não aceitava a teoria do valor de Marx, empregada na interpretação do lucro - ou da mais valia -, bem como da tendência à queda dessa taxa explicada por essa forma. Para ele, a fonte dos lucros, bem como de sua queda, viria através do processo de concorrência entre os capitais, mediante a introdução de novas mercadorias, ou seja, de inovação. A discussão dessa diferença teórica, contudo, não é o propósito deste trabalho. O ponto a ser retido é que a introdução de inovações no sistema econômico possui causas e efeitos econômicos e, por isso, merece receber um tratamento teórico sobre os seus determinantes.
} 
listas já estabelecidos, ou da burguesia, muito embora a ela se incorpore no caso de ser bem-sucedido. É alguém que se satisfaz em ver as coisas "ganharem vida". O que move as suas iniciativas - embora, como Schumpeter saliente, não sejam fáceis de identificar pode ser atribuído à ambição social, ao reconhecimento, entre outros ${ }^{8}$. No entanto, Schumpeter, em Capitalismo, Socialismo e Democracia, vai mudar de ponto de vista sobre quem introduz a inovação no sistema. A iniciativa individual, de pequeno porte, atomizada, necessitando de poupança externa através do crédito, é substituída pela criação do departamento de pesquisa e desenvolvimento (P\&D) da grande empresa em mercados mais concentrados, inclusive, minando as próprias bases do sistema ${ }^{9}$.

Embora sejam importantes as pistas conceituais estabelecidas por Schumpeter, ele não deixou um corpo teórico estruturado e bem desenvolvido sobre a geração e a difusão de inovações para fundamentar a mudança econômica. Essa tarefa tem sido abraçada pelos economistas denominados evolucionários ou neoschumpeterianos. A partir da década de 1970, estudos nessa linha iniciada por Schumpeter têm procurado fixar as bases teóricas para explicar os determinantes da tecnologia, em cujo fundamento há causas de natureza não apenas científica, mas também econômica. Tendo como foco essa temática, estabelece-se uma nova corrente de pensamento econômico, como denominada acima, que atribui ao progresso técnico uma posição central na análise no que concerne os elementos determinantes do processo de crescimento e desenvolvimento econômico. Trabalhos pioneiros nessa tradição como os de Nelson e Winter (1977, 1982[2006]), Rosenberg ([1982]2006), Freeman (1982, 1994) e Dosi (1982), entre outros, tratam a inovação como sendo endógena ao sistema econômico. O esforço teórico dessa corrente é estabelecer, então, um marco analítico acerca da inovação que permita entender o desenvolvimento do capitalismo em sua dinâmica evolutiva e que, nesse processo, também leve em conta a sua natureza histórica.

Os economistas neoschumpeterianos aceitam a concepção de Schumpeter da economia capitalista movimentando-se em desequilíbrio, na forma de ondas, alternando períodos de expansão e de depressão da atividade econômica. A origem principal desse movimento encontra-se no rejuvenescimento dos mercados, que se tornaram saturados pela maturidade das tecnologias em uso, através da introdução de novidades radicalmente diferentes na maneira de produzir, em matérias-primas ou fontes de energia utilizadas, e em novos bens e serviços comercializados e consumidos. Acei-

8 Esse ponto já foi mencionado por Costa (2006) em outro trabalho.

9 Essa mudança de opinião deu origem na literatura a um amplo debate sobre as chamadas hipóteses schumpeterianas, conhecido como Schumpeter: Mark I e Mark II (FAGERBERG, 2006). Em suma, o que promove a inovação? Os mercados atomizados de pequenos capitais ou os mercados concentrados formados por grandes empresas? Para uma literatura sobre a relação entre estruturas de mercados, tamanhos de firmas e inovação ver, por exemplo, Kamien e Schwartz ([1982]1989) e Cohen (1995). 
tam, igualmente, aquela distinção feita por Schumpeter entre inovações radicais e incrementais, mas buscam avançar novas categorias analíticas, ampliando essa taxonomia para incluir, entre outros conceitos, os de "sistemas tecnológicos", de "paradigmas tecnoeconômicos", e de "sistemas nacionais de inovação" (FREEMAN e PEREZ, 1988). No entanto, não é apenas nesse âmbito taxonômico que os esforços teóricos são dirigidos. Também há uma orientação em direção a um maior aprofundamento quanto à concepção de empresa e da maneira como esta se comporta.

Para a teoria neoschumpeteriana, embora os conhecimentos que informam a inovação possam provir tanto do ambiente interno da empresa - por exemplo, através de seu departamento de P\&D - quanto do ambiente externo - academia, laboratórios de pesquisa e outras instituições - é a empresa que, de um modo geral, introduz as inovações na economia. Segundo Nelson e Winter ([1982]2006), ao contrário da visão neoclássica que vê a firma como um agente individual possuidor de uma racionalidade substantiva, com pleno conhecimento dos caminhos alternativos a seguir, escolhendo aquele que otimiza a sua função objetivo, a visão evolucionária trata a empresa como tendo um comportamento satisfatório, agindo com racionalidade limitada, pois os indivíduos possuem capacidade cognitiva restrita e o mundo econômico em que atuam é complexo e incerto ${ }^{10}$. A partir desta concepção, os neoschumpeterianos entendem que as empresas desenvolvem rotinas que lhes orientem nas respostas às mudanças no ambiente e onde se encontram depositados os conhecimentos que elas utilizam em sua busca por novos produtos, métodos de produção, formas organizacionais e de comercialização.

Os conhecimentos codificados e tácitos de que a empresa dispõe são provenientes de múltiplas fontes e dependem de sua história passada, do regime tecnológico dominante em seu setor, de suas interações com outros atores econômicos e de seu domínio da técnica que utiliza em seu dia a dia. Além disso, dado que o ambiente econômico em que se move é permeado por incertezas e que a percepção das oportunidades de lucros é particularizada entre empresas, a diferenciação empresarial é a norma, em vez de sua homogeneidade. Como assinalado por Nelson (1991), as empresas diferem entre si e isso é importante para entender a geração e a difusão de inovação. A diferenciação entre empresas cria variedade tecnológica, o que é uma condição necessária para que haja escolha pelo mercado das mais desejáveis, com sua posterior difusão no tecido econômico, levando à evolução de produtos e de meios de produção e de organização. Assim, para a teoria evolucionária - tomando emprestados os princípios darwinistas empregados na evolução biológica e adaptando-os a uma abordagem econômica - a produção de variedade no sistema e a sua escolha através de mecanismos de sele-

\footnotetext{
${ }^{10}$ Essa é a ideia estabelecida por Simon (1979) e sobre a qual os neoschumpeterianos desenvolvem a concepção do comportamento da firma e o seu conceito de rotina.
} 
ção, onde se destaca o mercado, é o que confere dinamismo à economia e promove o desenvolvimento econômico. A implicação disso é que, na luta competitiva, como assinalado por Schumpeter ([1942]1984), há ganhadores e perdedores, e que essa "seleção" é um fator crucial para que haja desenvolvimento econômico.

Em seu movimento de expansão, o caminho a ser percorrido pela empresa vai ter como guia o paradigma tecnológico ${ }^{11}$ que é dominante em seu setor de atividade, condicionando as possibilidades para a obtenção de aumentos de produtividade ou de diferenciação de produto. Em todo caso, seja qual for o tipo de inovação que a empresa desenvolva, ela deverá ser selecionada pelo mercado quando da competição pelo poder de compra dos consumidores. A origem desse paradigma pode ser resultado de uma nova fonte de energia ou de novas matérias-primas ou, ainda, de um novo tipo de bem de capital, que se tornam fatores-chave, tanto econômica quanto tecnicamente, para amplos setores da economia. Tendo caráter pervasivo em suas oportunidades e consequências econômicas, essas inovações passam a constituir, junto com as instituições que lhe dão efetividade, um novo paradigma tecnoeconômico que irá orientar as decisões de investimentos na economia por um longo período (FREEMAN e PEREZ, 1988).

Uma característica importante do processo inovativo, salientada pela teoria evolucionária, refere-se ao seu caráter coletivo, com agentes apresentando diferentes capacitações, sendo resultado de um processo cumulativo de conhecimento, path-dependent, localizado, sujeito também ao ambiente institucional e de mercado em que ocorre (LUNDVALL e BORRÁS, 2006). A inovação tem característica ubíqua, com as suas fontes sendo provenientes de diferentes instituições. Isso, por sua vez, requer a interação entre distintos agentes e que resulta de um processo de aprendizagem que tem natureza sistêmica, em vez de se apresentar de forma unidirecional ou linear. Em uma economia de decisão descentralizada de consumo e de investimento, não há como saber a priori todas as possibilidades de uma dada inovação, nem as necessidades de seus usuários potenciais, bem como esses últimos não têm como conhecer os distintos usos possíveis a que o novo produto é capaz de atender. Com isso, a troca de informações entre diferentes agentes é fundamental, com o estabelecimento de canais por onde ocorre o fluxo de informações, desempenhando, assim, um papel relevante no processo de inovação.

Nesse sentido, o conceito-chave para tratar essa característica do processo inovativo é o de Sistema Nacional de Inovação. Elaborado inicialmente por Freeman (1987) para entender o desenvolvimento japonês no pós-Segunda Guerra Mundial, esse conceito ganhou adeptos como Lundvall (1988), Edquist ([1997]2011), Nelson (1988) e outros, que o tem utilizado para explicar as diferentes performances nacionais e o pro-

${ }^{11} \mathrm{O}$ paradigma tecnológico tem caráter setorial. Alguns setores são intensivos em ciência, outros se baseiam em escala ou são apenas usuários de tecnologia desenvolvida alhures (PAVITT, 1984). 
cesso de catching-up econômico. A maior ou menor distância cultural, geográfica, cognitiva e outras podem dificultar ou facilitar a interação e a transmissão de conhecimentos entre agentes produtores e usuários de tecnologia. Isso explicaria em maior grau as diferenças de desempenho inovativo de países do que a dotação de fatores de produção (LUNDVALL, 1988). O Sistema Nacional de Inovação pode ser entendido, então, de acordo com Perez (1991) e Freeman (1994), como um ambiente holístico onde se encontram não só a estrutura produtiva e um conjunto de instituições que fazem parte do sistema de ciência e tecnologia, mas também outros fatores de natureza social e institucional. Nas palavras de Freeman (1994, p. 484):

Entretanto, a maioria dos neoschumpeterianos, seguindo Lundvall (1992) e seus colegas, enfatiza que um "national system of innovation" é muito mais do que uma rede de instituições de apoio à $\mathrm{P} \& \mathrm{D}$; ele envolve redes de relações interfirmas e especialmente elos produtor-usuário de todos os tipos, assim como sistemas de incentivos e apropriabilidade, relações de trabalho e um amplo leque de instituições e políticas governamentais.

As implicações de política pública que se podem derivar desse retrospecto teórico entre as teorias evolucionária e neoclássica é que são radicalmente distintas entre si, como se mostrará a seguir.

\section{A POLÍTICA PÚBLICA PARA A INOVAÇÃO}

De um modo geral, a política pública para a inovação é estabelecida no âmbito da política industrial, que contempla uma ampla área de atuação, indo desde a política científica, tecnológica e de inovação, à ampliação da capacidade de produção de setores industriais, aos estímulos à estruturação de novos setores produtivos, passando pela política de concorrência, a política de comércio exterior e a política de desenvolvimento regional ${ }^{12}$. Aqui a política pública será tratada de maneira mais restrita, ou seja, com foco apenas na política de inovação ${ }^{13}$.

12 Vide, por exemplo, Cimoli, Dosi e Stiglitz (2009) e Bianchi e Labory (2006).

${ }^{13}$ No âmbito deste trabalho, as expressões "política de inovação" e "política tecnológica", como já referido na nota 1, são usadas de maneira intercambiável. Alguns autores (LUNDVALL e BORRÁS, 2006) fazem a distinção entre "política científica", "política tecnológica" e "política de inovação". O uso mais focado de política industrial, no sentido de política de inovação, pode ser encontrado também em Melo, Fucidji e Possas (2015). 


\subsection{O ENFOQUE NEOCLÁSSICO}

$\mathrm{Na}$ abordagem neoclássica tradicional, a política tecnológica é contemplada no âmbito da política pública geral. Esse enfoque emprega o conceito de "falhas de mercado" para orientar o papel exercido pelo Estado. As falhas são aquelas circunstâncias nas quais o neoclassicismo admite a presença do Estado na atividade econômica. Antes de investigar essa questão, convém explicitar um pouco mais os conceitos teóricos que fundamentam essa postura ${ }^{14}$.

Embora, como já mencionado na seção anterior, alguns economistas neoclássicos tentem tornar endógeno o progresso técnico, admitindo a existência de externalidades e de mercados menos que perfeitamente competitivos na produção de novos conhecimentos, o que domina na literatura sobre política pública dessa corrente é a presença de mercados de concorrência perfeita e de condições de ótimo de Pareto como critério de eficiência da atividade econômica ${ }^{15}$.

O enfoque teórico neoclássico centra sua abordagem metodológica em dois aspectos fundamentais: o equilíbrio e a análise estática. A análise de equilíbrio significa que o sistema econômico apenas ajusta-se às mudanças geradas externamente, mas sem alterar os seus parâmetros estruturais ${ }^{16}$. Alcançar o equilíbrio significa que as forças econômicas que, anteriormente, causaram sua perturbação cessaram de produzir seus efeitos. Não há tendência a mudanças. Elas, quando ocorrem, não se devem a movimentos endógenos, próprios do funcionamento da economia, mas de eventos que são estranhos a ela.

A análise estática, por sua vez, desconsidera a abordagem do processo em favor do estado, em seu sentido de não mudança. Ela trabalha com o tempo lógico e não leva em conta o tempo histórico. Como Stolper (1991) salienta o primeiro é reversível, enquanto o segundo é unidirecional. Ainda de acordo com Stolper, se os parâmetros não mudam, o tempo lógico pode ser introduzido no modelo e, assim, ser "dinamizado", mas acrescenta: "[e]volução não é a mesma coisa que dinâmica” (1991, p. 192). Nesse tipo de análise, o passado não tem importância nos acontecimentos presentes e nem no futuro. Os agentes não aprendem com a experiência e o conhecimento resume-se a uma questão de informação, que está disponível igualmente a todos.

\footnotetext{
14 As denominações para esse tipo de enfoque teórico são variadas. Por exemplo, Metcalfe (1995) chama essa perspectiva de "equilibrium view" (visão de equilíbrio), enquanto Lazonick (1994) o rotula de "mainstream economics" (principal corrente econômica, em tradução livre).

15 Uma passagem de olhos nos livros-texto de microeconomia ilustra esse quadro.

${ }^{16}$ Esse ponto também é lembrado por Stolper (1991).
} 
Pode-se dizer que, em linhas gerais, esse enfoque segue as ideias de Adam Smith, para quem, dada a existência de divisão do trabalho social, o mercado é o principal coordenador da atividade econômica em um regime de propriedade privada e de decisões tomadas de forma descentralizada. $\mathrm{O}$ que garante o adequado funcionamento da economia é a regulação através da livre concorrência. Para que ocorra dessa maneira, são necessárias algumas condições subsidiárias. Uma delas é que os agentes ajam de forma atomizada, sem condições de influir individualmente nos rumos dos fenômenos econômicos: é o que se conhece como mercado de concorrência perfeita. Outra condição é que a eficiência do sistema seja alcançada através da busca egoística por ganhos por parte dos agentes individuais, os quais têm racionalidade substantiva e pleno conhecimento das situações e, portanto, não erram, pois também não há incertezas $^{17}$, escolhendo aquelas decisões que maximizam a sua função utilidade, sujeita às suas restrições orçamentárias.

Em um mundo como esse retratado pela teoria neoclássica, não há lugar para o Estado na vida econômica. Ele é considerado uma imperfeição, dado que diferentemente do mercado, que é impessoal, o Estado caracteriza-se por sua discricionariedade. Dessa maneira, sua atuação nos mercados é entendida como distorcendo os preços relativos das mercadorias, o que interfere com a alocação eficiente de recursos na sociedade, isto é, aquela que seria realizada em condições de concorrência perfeita. Assim, a admissão da existência desse ente institucional se deve a fatores externos ao funcionamento econômico, como a garantia da ordem, dos direitos de propriedade e dos contratos. Mesmo que tenha que retirar recursos da economia para a manutenção do Estado, a ação deve ser feita de modo a não distorcer os preços relativos dos bens e serviços consumidos e dos fatores de produção, os quais são considerados indicadores dos desejos dos consumidores, dos valores a serem pagos aos proprietários dos recursos produtivos e de mão de obra, e dos bens e serviços fornecidos pelos produtores.

Infelizmente, para a teoria neoclássica, o mundo apresenta-se diferente do idealizado. Os mercados "falham" em cumprir o seu papel de coordenador da atividade econômica diante de determinadas situações, as quais a teoria neoclássica denomina, então, de "falhas de mercado". Essas distorções se manifestam quando: i) ocorrem assimetrias de informação, ou seja, uma das partes envolvida na negociação ou troca de mercado possui mais informações do que a outra. Esses são os casos para a ocorrência de "risco moral e de seleção adversa"; ii) há a existência de "poder de mercado", em que

\footnotetext{
${ }_{17}$ Quando muito se admite uma distribuição de probabilidade conhecida para tratar com eventos futuros, ou seja, reduzindo a incerteza a risco, o que permite o cálculo econômico, ao invés do "animal spirit" (NELSON, 1998).
} 
um dos agentes partícipe da transação tem condições de influir nos termos da troca ou de realizar práticas anticompetitivas. Essas são as características de estruturas de mercados imperfeitos: monopólio, oligopólio e concorrência monopolística, para usar a taxonomia dos livros-texto de microeconomia; iii) aparecem as "externalidades", que são estados de coisas em que os agentes se beneficiam ou sofrem perdas por eventos que ocorrem fora de seu mercado particular de troca; iv) observa-se a presença de "bens públicos", ou seja, aqueles tipos de bens em que não se podem discriminar os usuários que os consomem, em termos de excluí-los do mercado, bem como a não rivalidade no consumo desses bens ${ }^{18}$. Esses são os casos em que a teoria admite que o Estado intervenha na atividade econômica. Essa intervenção, porém, é apenas para corrigir essas falhas e não para substituir o mercado. A ação do ente público deve ser no sentido de recuperar aquelas condições em que o mercado se aproxima da concorrência perfeita. Essa estrutura de mercado é tomada, então, como um “benchmark", um guia de caráter normativo a orientar as ações de política pública.

A inovação é vista, então, pela ótica neoclássica dominante, sob a perspectiva das falhas de mercado, particularmente em relação à produção de conhecimento, que se caracteriza por ser incerto, indivisível, assumir aspectos de bem público, apresentar externalidades e ausência de garantias de apropriabilidade, não havendo, assim, incentivos para que as firmas envolvam-se nessa atividade ${ }^{19}$ (METCALFE, 1994, 1995, 2003; MALERBA, 1996; LUNDVALL e BORRÁS, 2006). Sob esse aspecto, o mercado produz resultados que são socialmente ineficientes, pois não atende aos requisitos de uma situação de "ótimo de Pareto", a qual só é alcançável em mercados de concorrência perfeita. Nesse tipo de estrutura de mercado, segundo a teoria neoclássica, não haveria incentivos para um agente individual empreender esforços inovativos, pois ele não teria garantias de se apropriar dos benefícios pela introdução de algo novo no mercado, dado

${ }^{18}$ Como já referido, os novos modelos neoclássicos de crescimento consideram o conhecimento como um tipo de bem público, que possui características de não rivalidade, mas sendo parcialmente excludente. Ou seja, a firma que investe em P\&D tem condições de, parcialmente, se apropriar dos benefícios da inovação. Igualmente, aceitam que os novos conhecimentos apresentem retornos crescentes, de modo que os mercados sejam imperfeitamente competitivos. Porém, como salientado por Nelson (1998), essas características de há muito já estavam presentes naqueles estudos empíricos (aqui, Nelson cita explicitamente um relatório de Moses Abramovitz produzido em 1952), que procuravam conhecer a natureza da inovação. A novidade dos "novos" modelos de crescimento endógeno, ainda segundo Nelson (1998), estaria apenas em sua formalização matemática, não acrescentando nada de novo ao já conhecido e questiona, ainda, porque os autores desses modelos incorporam algumas características da inovação e omitem outras (por exemplo: a incerteza, a diferenciação entre empresas e a presença de outras instituições, como as universidades). A sua resposta é que isso permite a esses modelos continuarem na linha neoclássica de análise de equilíbrio geral.

${ }^{19}$ Com a ressalva dos modelos de crescimento endógeno, como visto na nota de pé de página anterior. 
que qualquer agente teria livre acesso a todas as informações, a bens e serviços, e a fatores de produção relevantes. Nesse caso, a teoria admite que o Estado faça a correção dessa "falha", mediante a instituição de algum mecanismo de proteção ao inovador, como o sistema de patentes ou de copyright (METCALFE, 2003). Já no caso dos modelos de crescimento endógeno, admite-se que o Estado possa atuar no fornecimento de educação geral (ou no subsídio à formação de capital humano, segundo Romer (1990) e no financiamento à pesquisa básica, mas sem exercer discriminações (LUNDVALL e BORRÁS, 2006). Ou seja, a recomendação normativa geral para a condução da política tecnológica é a de que seu fomento não crie distorções nos preços relativos para não modificar a alocação considerada "eficiente", isto é, aquela obtida em condições de mercado. É de se notar que a visão negativa que a teoria neoclássica tem do Estado é, como mencionada em Krueger (1990), que a intervenção produz resultados ineficientes: em alguns casos, disputa recursos que seriam mais bem aplicados naquelas atividades que dispõem de vantagens comparativas; produz custos cuja atribuição é injusta ou ineficiente, pois não identifica claramente os que pagam e os que são beneficiários da intervenção; e, além disso, o agente (indivíduo) público não tem porque ser diferente do privado, pois também age egoisticamente, visando os seus próprios interesses.

Segundo Mazzucato (2014), a ideia de que o Estado só deve intervir nos casos em que o mercado falha baseia-se em uma visão distorcida e ideologizada de seu papel na economia. A visão negativa do ente público é difundida na sociedade através de um discurso em que o Estado é apresentado como ineficiente, pesado e incapaz de gerar dinamismo econômico, enquanto à iniciativa privada são atribuídas todas as propriedades positivas para alcançar o crescimento e o bem-estar da sociedade. Mas, como extensamente ilustrado por Mazzucato (2014), quando se perscruta mais minuciosamente a história das principais inovações que revolucionaram a vida em sociedade, constata-se a presença ativa, visionária e corajosa do Estado na raiz desses empreendimentos, os quais não vingariam se dependesse apenas do tal "animal spirits" privado ${ }^{20}$.

Note-se, ainda, que, em mercados de concorrência perfeita, a própria ideia de inovação não faz muito sentido, pois, se os agentes são homogêneos e têm acesso às mesmas informações, decorre daí que ou todos eles fazem simultaneamente o mesmo tipo de inovação, com duplicação de esforços, ou ninguém inova. A própria necessidade de inovação é irrelevante, pois se qualquer empresa vende tudo o que produz ao preço de

\footnotetext{
20 "[...] a maioria das inovações radicais, revolucionárias, que alimentaram a dinâmica do capitalismo - das ferrovias à internet, até a nanotecnologia e farmacêuticas modernas - aponta para o Estado na origem dos investimentos 'empreendedores' mais corajosos, incipientes e de capital intensivo" (MAZZUCATO, 2014, p. 26).
} 
mercado vigente, não haveria motivos para introduzir inovações para superar dificuldades, dado que estas são inexistentes. A inovação, quando introduzida no mercado, provém de fora do sistema, sendo acessível a todos os agentes. Enfim, o conceito de "falhas de mercado" não fornece uma base teórica adequada para orientar a política pública (CIMOLI et al., 2009) ${ }^{21}$.

\subsection{A PERSPECTIVA EVOLUCIONÁRIA}

O que distingue o enfoque evolucionário do neoclássico é a sua preocupação com a mudança econômica e a adaptação tecnológica. Nesse esforço por entender as causas das transformações econômicas que ocorrem na sociedade, essa teoria substitui os conceitos de equilíbrio e de análise estática - como organizadores do material a ser pesquisado - pelas categorias de processo e de mudança, ou seja, de evolução.

A política pública na área da inovação, na perspectiva evolucionária, deve estar preocupada com a geração de conhecimentos e a sua aplicação no desenvolvimento de novas tecnologias, aumentando a variedade de produtos, de processos produtivos e de formas organizacionais que sejam superiores àquelas já estabelecidas. A questão, então, é como as empresas lidam com as mudanças no ambiente econômico, particularmente com as de cunho tecnológico, em vez de como otimizam a sua função objetivo particular. As ações de política têm de estar voltadas para promover o aprendizado nas suas diferentes formas (por exemplo, learning-by-doing, learning-by-using, learning-by-interacting), de modo a criar novidades e sua difusão na economia. Esse aprendizado, além dos esforços feitos individualmente, resulta de absorção de conhecimentos produzidos por outras instituições, como universidades, laboratórios públicos, consultorias independentes, bem como com fornecedores de bens e serviços e com clientes, mediante um processo interativo no âmbito dessa divisão de trabalho social. Desse modo, o conceito de sistema de inovação mostra-se mais abrangente na explicação do processo inovativo e, portanto, mais promissor como guia para a política pública do que aquele das falhas de mercado.

Em suas diretrizes, a política pública pode ser “diffusion oriented”, visando o fortalecimento dos agentes em uma dada trajetória ou fronteira tecnológica, estimulando o

${ }^{21}$ Em um trabalho no qual buscam discutir a experiência histórica brasileira no que se refere ao papel da política industrial no desenvolvimento econômico, Suzigan e Furtado (2006) rejeitam o enfoque das "falhas de mercado" e optam pela abordagem neoschumpeteriana/evolucionária, com seu foco em inovação como base para avaliar os sucessos e os percalços da política industrial aplicada no país. 
processo de catching-up nessa trajetória, ou "mission oriented", em que busca o desenvolvimento de alguma área de conhecimento ou de setor de atividade, ou, ainda, incentivando a incursão em novos campos, ou em novos paradigmas tecnológicos ${ }^{22}$. Contudo, é importante frisar, como lembrado por Metcalfe (1995), que o fato de a política pública evolucionária tratar com a hipótese de que o mercado, por si só, não seja capaz de coordenar os esforços em direção à inovação, não significa que o policy maker público não esteja sujeito a erros e a falhas ${ }^{23}$. Entre outras, essas incorreções referem-se às dificuldades em prever a trajetória futura da inovação, à possibilidade de realizar diagnósticos imprecisos sobre a dinâmica econômica ou de efetuar apostas errôneas em seus incentivos, cometendo erros semelhantes aos das empresas privadas em suas estratégias. Entretanto, dado que a inovação resulta de um processo interativo, com características sistêmicas, abrangendo diferentes instituições, o ente público, devido, também, à sua legitimidade política, está em melhores condições de coordenar as ações desses atores envolvidos no processo de inovação do que a firma ou o agente individual, que está preocupado, primordialmente, com a sua função objetivo particular (METCALFE, 2003).

A política pública evolucionária vê as questões contidas nas chamadas "falhas de mercado" sob uma perspectiva diferente daquela de matiz ortodoxa. Para a teoria evolucionária, as assimetrias de informações e de conhecimento, por exemplo, devem ser consideradas como fazendo parte da natureza do sistema. As empresas, em sua sobrevivência e crescimento no mercado, se vêem envolvidas em um processo de busca por novos produtos, novos processos de produção e comercialização, por novas formas organizacionais, de modo a se distinguirem de suas concorrentes, atraindo a atenção e o poder de compra dos consumidores e, assim, superarem as rivais na luta competitiva. Esse movimento requer necessariamente a diferenciação de comportamentos. O caminho trilhado é o da inovação. A competição pode ser por preço ou em outro atributo do produto, como qualidade, design, serviço pós-venda, marca e outros. Como Schumpeter ([1942]1984) enfatizou, a competição que conta é, portanto, a tecnológica.

No que se refere ao poder ou à concentração de mercado pelas empresas, com os seus possíveis efeitos deletérios, como abusos de preços e práticas anticompetitivas,

22 Como enfatizada por Mazzucato (2014), essa visão de "missão" tem sido observada nas ações do Estado no campo da inovação.

${ }^{23}$ Edquist (2011) argumenta que o fato de o Estado desempenhar um papel através da política de inovação, em função desta apresentar um caráter sistêmico, não significa que o simples incentivo genérico seria capaz de gerar inovação. É necessário que se faça um diagnóstico adequado de que tipo de inovação o sistema se mostra carente. A alocação de recursos para P\&D sem uma identificação precisa de onde o sistema de inovação "falha" levaria a desperdícios. Edquist prefere o uso do termo "problems" em vez de "systems failures" para evitar conotações com a expressão "market failures" da teoria neoclássica. 
a teoria evolucionária não descarta a necessidade de uma política de concorrência que coíba essas ações. A concentração industrial, de um modo geral, resulta de processo seletivo de mercado, que reduz a variedade e não necessariamente resulta de práticas anticompetitivas ou de domínio de mercado. Isso não significa que, em havendo concentração - devido à própria evolução do setor ou de monopólio natural -, não possam ocorrer abusos. A política de concorrência e de regulação deve inibir essas práticas, mas sem prejudicar o comportamento em direção à inovação. Em outras palavras, a política de concorrência e a política tecnológica devem ser complementares (METCALFE, 1995). Possas e Borges (2009, p. 249) também comungam da ideia de que o conceito de falha de mercado é limitado, inclusive, para tratar da política de competição e de regulação. Na visão dos autores, em vez de substituir o mercado que "falhou", o Estado deveria prover os incentivos e as penalidades em direção ao fortalecimento do comportamento inovativo. A preocupação deveria ser não com a eficiência estática, mas com a eficiência dinâmica através do mecanismo de seleção pelo mercado.

A política tecnológica deve promover a criação de novidades no mercado, incentivando a inovação por empresas já estabelecidas ou por novos entrantes, de modo a contestar as práticas e produtos vigentes. Assim, a concorrência deve ser vista em seu sentido próprio de disputa, de embates entre capitais, ou seja, em seu aspecto dinâmico e não como estado, ou estrutura, através apenas do número de empresas existentes no mercado ou de índices de concentração ${ }^{24}$.

As externalidades e os bens públicos, outras das fontes das falhas de mercado, são vistas de maneira diferente pela teoria evolucionária. De acordo com Metcalfe (2003),

24 De resto, esse ponto já havia sido mencionado por Schumpeter ([1942]1984) no capítulo 8 intitulado "Práticas Monopolistas", no qual chama a atenção que a existência de uma posição monopolista não deve ser vista de maneira estática, "ex visu de um dado ponto no tempo", mas sim de uma perspectiva dinâmica em que essa posição possa decorrer da introdução de algo novo na economia. Os lucros extraordinários daí obtidos devem ser encarados como passageiros, um prêmio pela novidade e não como decorrente de um abuso de poder, reduzindo a produção ou mantendo preços elevados. Igualmente, a comparação de estruturas de mercados imperfeitas (monopólio, oligopólio) com a concorrência perfeita, que aparece em manuais de microeconomia (FERGUSON, 1971, p. 250-251), onde se procura mostrar que essa última forma de mercado é mais eficiente, não tem muito sentido em termos factuais, pois se baseia na hipótese de que, ao se passar de uma estrutura de concorrência perfeita para uma de monopólio ou oligopólio, o aumento da escala de produção não altera a estrutura de custos das empresas, ou seja, não ocorrem economias de escala pela maior concentração do mercado. É por isso que, ao comparar a concorrência perfeita como o monopólio (mediante o uso gráfico, por exemplo), o preço de monopólio é maior do que o preço em concorrência perfeita e a sua produção é menor do que nessa última, dado que, em monopólio, a receita marginal situa-se abaixo da receita média (ao contrário da concorrência perfeita em que as duas são iguais). Isso se deve, em ambos os casos a que a maximização de lucro ocorre na intersecção das curvas de receita e custo marginal. 
o tratamento dado pela teoria das falhas de mercado aos spillovers provenientes das inovações é inadequado, pois considera que os transbordamentos ocorrem apenas entre concorrentes diretos. Essa visão despreza outros atores e setores produtivos que podem se beneficiar direta ou indiretamente de inovações realizadas fora dos mercados em que atuam. No que se refere às propriedades de bens públicos dos conhecimentos, a ideia da imitação ou de seu uso sem o pagamento de compensações ao inovador, a abordagem das falhas de mercado também é simplista. Ela considera que a apropriação e o uso do conhecimento sejam sem custos, sendo de fácil aquisição e aplicação. Conforme Metcalfe (2003, p. 126):

[...] a fraqueza do modelo do conhecimento como bem público é que ele coloca o transmissor e o receptor do conhecimento na mesma base e ignora completamente a importância do modo e do processo de intercomunicação. Isto simplesmente não ajuda. Pode ser barato transmitir informação, mas a interpretação da informação, sua tradução em conhecimento prático nunca é sem custo.

Enfim, dada a natureza sistêmica envolvida na produção e difusão de novidades na economia, a política pública evolucionária para a inovação deve estar preocupada em fortalecer esse processo. O escopo institucional alargado com que a política pública trabalha implica em reconhecer as particularidades e os objetivos dos diferentes agentes que são foco das ações. Em outras palavras, a natureza da política endereçada ao fortalecimento da geração e da difusão de conhecimento básico ou fundamental não tem o mesmo caráter daquela que visa promover a capacitação da empresa privada. Igualmente, a política não necessita ser homogênea para os diferentes setores produtivos da economia, os quais apresentam distintas intensidades tecnológicas, dadas as características setoriais da inovação.

\section{CONSIDERAÇÕES FINAIS}

A inovação é reconhecidamente considerada como se constituindo em um dos principais fatores de crescimento econômico e de melhoria das condições de vida das sociedades. Em anos recentes, ela ganhou proeminência na agenda de política pública dos países, independentemente de seus estágios de desenvolvimento. Considera-se que, na chamada "sociedade do conhecimento", cuja expressão é empregada para descrever o mundo atual, os bens e serviços, seja em seu conteúdo, seja em sua forma de produzir, estarão baseados - ou terão seu valor adicionado - muito mais em fatores associados a conhecimentos do que em materiais. 
A política de inovação nas últimas décadas ampliou os seus horizontes e formas de atuação com o fortalecimento da teoria econômica evolucionária. Os avanços teóricos proporcionados por essa corrente de pensamento econômico permitiram novas perspectivas para as ações do governo em relação à inovação como fator na promoção do progresso social. A particularidade dessa forma de pensar é que, para ela, a inovação não apresenta apenas caráter técnico, mas possui também determinantes econômicos, e como tal, pode ser tratada no âmbito da teoria econômica, constituindo-se em uma área de atuação e de pesquisa dos economistas.

De um modo geral, a preocupação com a inovação sempre esteve presente nos estudos dos economistas. Entretanto, o interesse concentrou-se mais em seus efeitos do que em suas causas econômicas, como na teoria clássica. Marx, por sua vez, estava profundamente preocupado com o progresso das forças produtivas da sociedade, mas o seu objeto de análise era desvendar as leis gerais de desenvolvimento do capitalismo e a mudança histórica. Embora a tecnologia tenha desempenhado um importante papel em sua análise do capitalismo, não há, em Marx, um tratamento específico para os determinantes da inovação.

A natureza do objeto investigado, muitas vezes, levou os esforços teóricos a privilegiar outras dimensões da atividade econômica, como no caso da teoria keynesiana ao focar na insuficiência de "demanda efetiva" como a causa do desemprego, desconsiderando a possível influência de fatores ligados à inovação.

A abordagem neoclássica, em que pese não ter uma teoria consistente da inovação, exerce, contudo, uma influência nessa área mesmo que indireta, particularmente no que se refere à política pública. Essa teoria nega um papel ativo para o Estado na economia, admitindo a sua presença somente naquelas situações em que o mercado falha em seu papel de coordenar a atividade econômica. A ação do Estado, então, é somente para corrigir essas falhas. É nesse âmbito que a teoria vê a inovação, a qual é interpretada como possuindo características de bem público, como no enfoque mais tradicional, ou não rival e parcialmente excludente, como no caso dos modelos de crescimento endógeno. Porém, mesmo o esforço de procurar endogeneizar o conhecimento nessa teoria é limitado, pois está alicerçado em agentes otimizadores, papel limitado das instituições e da firma, entre outros. Enfim, o conceito de "falhas de mercado" é inadequado para orientar a política pública, dado que elas são fruto do próprio mecanismo de funcionamento dos mercados e não de suas "imperfeições".

Os esforços teóricos para compreender o fenômeno da inovação na economia, colocando-a no centro da investigação, provêm da corrente evolucionária de pensamento econômico a partir das contribuições de Joseph Schumpeter. Para essa escola, a inovação deve ser vista como tendo características sistêmicas, resultado de distintas fontes na produção de conhecimento. A interação entre essas diferentes origens é que 
dá base para o processo inovativo. O conceito relevante para tratar com esse processo é o de sistema de inovação. O papel da política pública é fortalecer esse sistema, de modo a promover a criação de variedade, seja através de ações que permitam que os agentes adaptem-se às mudanças, seja estimulando os esforços em direção a novas fronteiras tecnológicas. Nesse sentido, o foco da política pública não é o alcance da eficiência em si, no sentido de algum ótimo econômico, mas sim com a geração e a difusão de variedade no sistema. É isso que produzirá crescimento econômico e bem-estar social. Igualmente, o processo seletivo de concorrência deve ser visto em seu aspecto dinâmico e não de maneira estática, apenas como estrutura. Enfim, a teoria evolucionária traz contribuições à política pública, fornecendo conceitos que permitem melhor orientar as suas ações na promoção do desenvolvimento econômico.

\section{REFERÊNCIAS}

ABRAMOVITZ, M. “Tendencias de los recursos y de la producción em los Estados Unidos desde 1870”. In: ROSENBERG, N. (Ed.). Economia del Cambio Tecnológico. México: Fondo de Cultura Económica, [1956]1979.

BIANCHI, P.; LABORY, S. “From 'old' industrial policy to 'new' industrial development policies". In: BIANCHI, P.; LABORY, S. (Eds.). International Handbook on Industrial Policy. Cheltenham, UK/Northampton, USA: Edward Elgar, 2006.

CIMOLI, M.; DOSI, G.; STIGLITZ, J. E. “The political economy of capabilities accumulation: the past and future of policies for industrial development”. In: CIMOLI, M.; DOSI, G.; STIGLITZ, J. E. (Eds.). Industrial policy and development: the political economy of capabilities accumulation. Oxford/New York: Oxford University Press, 2009.

CIMOLI, M. et al. "Institutions and policies shaping industrial development: an introductory note”. In: CIMOLI M.; DOSI, G.; STIGLITZ, J. E. (Eds.). Industrial policy and development: the political economy of capabilities accumulation. Oxford/New York: Oxford University Press, 2009.

COHEN, W. "Empirical studies of innovative activity". In: STONEMAN, P. (Ed.). Handbook of the economics of innovation and technological change. Oxford: UK/Cambridge, USA: Blackwell, 1995.

COSTA, A. B. O desenvolvimento econômico na visão de Joseph Schumpeter. Cadernos IHU Ideias, Instituto Humanitas Unisinos, ano 4, n. 47, 2006.

DOSI, G. Technological paradigms and technological trajectories. Research Policy, v. 11, p. 147 $162,1982$.

EDQUIST, C. Design of innovation policy through diagnostic analysis: identification of systemic problems (or failures). Industrial and Corporate Change, v. 20, n. 6, p. 1725-1753, 2011.

EDQUIST, C. "Systems of Innovation approaches - their emergence and characteristics". In: EDQUIST, C. (Ed.). Systems of Innovation: technologies, institutions and organizations. London/New York: Routledge, [1997]2011. 
FAGERBERG, J. "Innovation: a guide to the literature". In: FAGERBERG, J.; MOWERY, D. C.; NELSON, R. R. (Eds.). The Oxford Handbook of Innovation. Oxford/New York: Oxford University Press, 2006.

FREEMAN, C. The economics of technical change. Cambridge Journal of Economics, v. 18, p. 463-514, 1994.

FREEMAN, C. Technology policy and economic performance: lessons from Japan. London/New York: Pinter Publishers, 1987.

FREEMAN, C. The Economics of Industrial Innovation. London/New York: Pinter Publishers, 1982.

FREEMAN, C.; PEREZ C. "Structural crises of adjustment: business cycles and investment behaviour". In: DOSI, G. et al. (Eds.). Technical change and economic theory. London/New York: Pinter Publishers, 1988.

FERGUSON, C. E. Teoría Microeconómica. México: Fondo de Cultura Económica, 1971.

HICKS, J. Perspectivas Econômicas: ensaios sobre moeda e crescimento. Rio de Janeiro: Zahar Editores, [1977]1978.

KAMIEN, M. I.; SCHWARTZ, N. L. Estructura de mercado e innovación. Madrid: Alianza Editorial, [1982]1989.

KEYNES, J. M. A teoria geral do emprego do juro e da moeda. São Paulo: Abril Cultural, [1936]1983.

KRUEGER, A. O. Government failures in development. Journal of Economic Perspectives, v. 4, n. 3, 1990, p. 9-23.

LAZONICK, W. Business organization and the myth of the market economy. New York: Cambridge University Press, 1994.

LUNDVALL, B. A.; BORRÁS, S. “Science, technology, and innovation policy”. In: FAGERBERG, J.; MOWERY, D. C.; NELSON, R. R. (Eds.). The Oxford Handbook of Innovation. Oxford/ New York: Oxford University Press, 2006.

LUNDVALL, B. A. "Innovation as an interactive process: from user-producer interaction to the national systems of innovation". In: DOSI, G. et al (Eds.). Technical change and economic theory. London/New York: Pinter Publishers, 1988.

LUNDVALL, B. A. (Ed.). National systems of innovation: towards a theory of innovation and interactive learning. London/Nova York: Pinter Publishers, 1992.

MALERBA, F. Public policy in industrial dynamics: an evolutionary perspective. Milan: Bocconi University, Dec. 1996, p. 17, mimeo.

MARSHALL, A. Princípios de Economia: tratado introdutório. V. I e II. São Paulo: Abril Cultural, $[1890 / 1920] 1982$.

MARX, K. O Capital: crítica da economia política. Coleção Os Economistas. V. I (Tomos 1 e 2). São Paulo: Abril Cultural, [1867]1983/1984.

MARX, K.; ENGELS, F. Manifesto Comunista. São Paulo: Boitempo, [1848]2010.

MARX, K. Miseria de la Filosofia. Buenos Aires: Siglo Veintiuno Argentina Editores, [1847]1974.

MAZZUCATO, M. O estado empreendedor: desmascarando o mito do setor público vs. setor privado. São Paulo: Portfolio-Penguin, 2014. 
MELO, T. M.; FUCIDJI, J. R.; POSSAS, M. L. Política industrial como política de inovação: notas sobre hiato tecnológico, políticas, recursos e atividades inovativas no Brasil. Revista Brasileira de Inovação, Campinas (SP), v. 14, n. esp., p. 11-36, jul. 2015.

METCALFE, S. J. Equilibrium and evolutionary foundations of competition and technology policy: new perspectives on the division of labour and the innovation process. Revista Brasileira de Inovação, v. 2, n. 1, p. 111-146, jan./jun. 2003.

METCALFE, S. J. “The economic foundations of technology policy: equilibrium and evolutionary perspectives". In: STONEMAN, P. (Ed.). Handbook of the Economics of Innovation and Technological Change. Oxford, UK/Cambridge, USA: Blackwell, 1995.

METCALFE, S. J. Evolutionary economics and technology policy. The Economic Journal, v. 10, p. 931-944, jul.1994.

NELSON, R. R. The agenda for growth theory: a different point of view. Cambridge Journal of Economics, v. 22, p. 497-520, 1998.

NELSON, R. R. How new is new growth theory? Challenge, v. 40, n. 5, p. 29-58, set./out. 1997.

NELSON, R. R. Why do firms differ, and how does it matter? Strategic Management Journal, v. 12, p. 61-74, 1991.

NELSON, R. R. "Institutions supporting technical change in the United States". In: DOSI, G. et al. (Eds.). Technical change and economic theory. London/New York: Pinter Publishers, 1988.

NELSON, R. R.; WINTER, S. G. An evolutionary theory of economic change. Cambridge, MA/ London: The Belknap Press of Harvard University Press, [1982]2006.

NELSON, R. R.; WINTER, S. G. In search of useful theory of innovation. Research Policy, v. 6, p. 36-76, 1977.

PAVITT, K. Sectoral patterns of technical change: towards a taxonomy and a theory. Research Policy, v. 13, p. 343-373, 1984.

PEREZ, C. National Systems of Innovation, competitiveness and technology: A discussion of some relevant concepts and their practical implications. Santiago de Chile: ECLAC, mai. 1991, mimeo.

PETIT, P. "Employment and technological change". In: STONEMAN, P. (Ed.). Handbook of the economics of innovation and tecnological change. Oxford, UK/Cambridge, USA: 1995.

POSSAS, M. L.; BORGES, H. “Competition policy and industrial development”. In: CIMOLI, M.; DOSI, G.; STIGLITZ, J. E. (Eds.). Industrial policy and development: the political economy of capabilities accumulation. Oxford/New York: Oxford University Press, 2009.

RICARDO, D. Princípios de Economia Política e Tributação. São Paulo: Abril Cultural, [1817/1821]1982.

ROMER, P. M. Endogenous technological change. Journal of Political Economy, v. 98, n. 5, p. 71$102,1990$.

ROMER, P. M. Increasing returns and long-run growth. Journal of Political Economy, v. 94, n. 5, p. 1002-1037, out. 1986.

ROSENBERG, N. Por dentro da caixa preta: tecnologia e economia. Campinas, SP: Editora da Unicamp, [1982]2006. 
SCHUMPETER, J. A. Capitalismo, socialismo e democracia. Rio de Janeiro: Zahar Editores, [1942]1984.

SCHUMPETER, J. A. Business cycles: a theoretical, historical and statistical analysis of the capitalist process. New York: McGraw-Hill Inc., 1939.

SCHUMPETER, J. A. A teoria do desenvolvimento econômico. São Paulo: Abril Cultural, [1911/1934]1982.

SIMON, H. A. Rational decision making in business organizations. American Economic Review, v. 69, n. 4, p. 493-513, set. 1979.

SMITH, A. Investigación sobre la naturaleza y causas de la riqueza de las naciones. México: Fondo de Cultura Económica, [1776]1958.

SOLOW, R. "El cambio técnico y la función de producción agregada". In: ROSENBERG, N. (Ed.). Economia del Cambio Tecnológico. México: Fondo de Cultura Económica, [1957]1979.

STOLPER, W. F. The theoretical bases of economic policy: the Schumpeterian perspective. Journal of Evolutionary Economics, v. 1, p. 189-205, 1991.

SUZIGAN, W.; Furtado, J. Política industrial e desenvolvimento. Revista de Economia Política, v. 26, n. 2 (102), p. 163-185, abr./jun. 2006.

VERSPAGEN, B. "Innovation and economic growth". In: FAGERBERG, J.; MOWERY, D, C.; NELSON, R. R. (Eds.). The Oxford Handbook of Innovation. Oxford/New York: Oxford University Press, 2006. 